\title{
LOCAL HEAT ENERGY TRANSPORT ANALYSES IN GALLIUM-INDIUM-NITRIDE/GALLIUM NITRIDE HETEROSTRUCTURE BY MICROSCOPIC RAMAN IMAGING EXPLOITING SIMULTANEOUS IRRADIATION OF TWO LASER BEAMS
}

\author{
Shungo Okamoto', Naomichi Saito, Kotaro Ito', Bei Ma1, Ken Morita', Daisuke lida², Kazuhiro \\ Ohkawa $^{2}$, Yoshihiro Ishitani ${ }^{1}$ \\ ${ }^{1}$ Chiba University, Chiba City, Japan \\ ${ }^{2}$ King Abdullah University of Science and Technology, Thuwal, Saudi Arabia
}

\begin{abstract}
Local heat transport in two $G a_{x} I n_{1-x} N / G a N$-heterostructures on sapphire substrates is investigated by microscopic Raman imaging using two lasers of $532 \mathrm{~nm}$ (Raman observation) and $325 \mathrm{~nm}$ (heat generation and Raman observation), which enables the separation of heat generation and Raman observation positions. It is found that $E_{2}$ (high) and $A_{1}(L O)$ modes of the $G a_{0.84} I n_{0.16} \mathrm{~N}$ layer exhibit mutually different characteristics, which indicates the analysis of the occupation of the $A_{1}(L O)$ mode is available. E $E_{2}(h i g h)$ mode of the GaN layer observed by the 532-nm laser reveals that the transport of the heat energy generated in the $G a_{0.84} I n_{0.16} N$ layer to the GaN under layer is blocked in the high-density area of misfit dislocation in the vicinity of the heterointerface.
\end{abstract}

Keywords: Phonon transport, Raman imaging, III-nitrides

\section{INTRODUCTION}

It is known that the operating characteristics of electronic devices deteriorate with increasing temperature [1-3]. For the ultraviolet emission mechanism, for example, the population distribution in excitonic states varies depending on phonon occupation or phonon temperature, and an expansion of the population distribution reduces the excitonic emission rate and efficiency [4-7]. Electron scattering in transistors yields device heating, which increases the rate of electron scattering by phonons. III-nitrides, which are utilized for visible - ultraviolet LED, laser diodes, and high electron mobility transistors, have high interaction strength with longitudinal optical (LO) phonon. In many cases, these crystals are grown on a substrate with high lattice mismatch, which means the existence of high-density crystal defects in the vicinity of the interface with the substrate. Previously, a lot of discussions have been conducted on the effects of crystal defects on thermal energy transport. Some references indicate that threading dislocations give eminent effects on energy transport when the density is over $10^{8}-10^{10}$ $\mathrm{cm}^{-2}[8,9]$. One such article indicates that voids are major defects suppressing thermal transport [10]. However, microscopic local imaging of heat transport at a specific defect is still a challenging issue.

The radiation efficiency of exciton is reduced by the population distribution among the principal quantum number states induced mainly by the strong interaction with LO phonons [4-7]. This result indicates that it is necessary to analyze the transport of LO phonons separately from acoustic phonons. In Raman measurements, mode-separated phonon properties can be obtained, which is an advantage compared with the pump-probe method of photoreflectivity $[11,12]$. It is known that in Raman scattering measurements, two spectra obtained using two laser beams of different wavelengths provide the depth profile of the strain field of a two-layer stacking structure [13], while analyses of heat transport at a heterointerface or crystal defects require the additional element of simultaneous incidence of two laser beams, the pump (heating) and probe (Raman measurement) system, and the control of irradiation positions in order to distinguish the heating and probing areas. Micro-Raman mapping has been utilized for the analysis of spatially local temperatures $[14,15]$ and heat generation in transistors [15-18]. Various methods including this technique have been studied for the analysis of heat transport across heterointerfaces or superlattices [19-27]. However, microscopic local imaging of mode-separated phonon transport at a specific defect is still a challenge.

GaInN and AlInN alloys are future materials for high power transistors and optical devices in the green gap in laser devices. Characteristic properties of local strain, fluctuation of energy gap due to spatial nonuniformity of alloy composition, carrier dynamics, and so forth are now under investigation, while nonuniform thermal conduction remains unclear. As the difference in lattice constant at a heterointerface extends to 14 $\%$, which is for AlN and InN, misfit dislocations can be generated in the vicinity of the heterointerfaces $[28,29]$. 

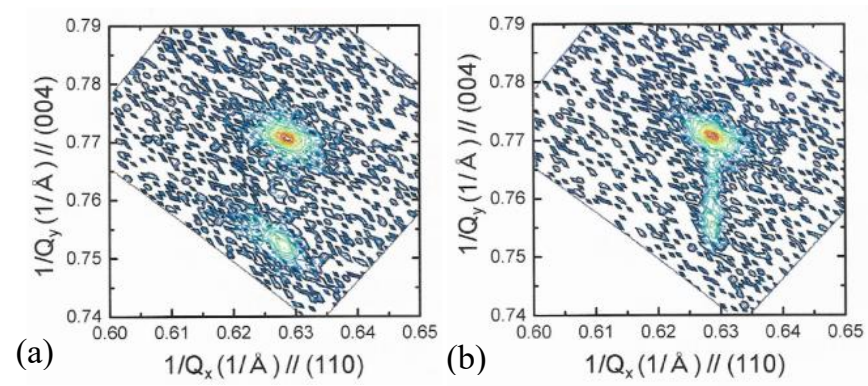

FIGURE 1: RECIPROCAL LATTICE SPACE MAPPING BY XRAY DIFFRACTION FOR SAMPLE A (a), AND SAMPLE B (b).

In the previous letter, we have substantialized the advantage of our pump (heating) - probe (Raman measurement) method using a sample with misfit dislocations (MDs) at a GaInN/GaN heterointerface. In this paper, we contrast the characteristic properties of the heat transport at the heterointerface including MDs with the properties of a sample with a far lower density of MDs. In the previous report, we have not discussed the difference in the probed physical process between phonon modes. In this report, Raman imaging results of the $A_{1}(L O)$ mode $\left(\mathrm{A}_{1}{ }^{\mathrm{L}}\right)$ are discussed in comparison with the results on the $\mathrm{E}_{2}$ (high) mode $\left(\mathrm{E}_{2}{ }^{\mathrm{H}}\right)$, and the discussion is extended to the characteristic properties of the LO phonon transport.

\section{MATERIALS AND METHODS}

Two $\mathrm{Ga}_{x} \mathrm{In}_{1-x} \mathrm{~N}$ samples $\mathrm{A}$ and $\mathrm{B}$ with a thickness of $110 \mathrm{~nm}$ were grown on $\mathrm{n}-\mathrm{GaN}$ layers on sapphire substrates by a metalorganic vapor phase epitaxy system [31,32]. Sample A has an alloy composition $x=0.84$ for the crystal under the pseudomorphic condition. Sample B has graded $x$, which is continuously varied from 0 to 0.17 toward the surface. No layer with any constant $x$ is included. FIGURE 1 shows reciprocal lattice space mapping images. The broad diffraction image of the $\mathrm{Ga}_{x} \mathrm{In}_{1-x} \mathrm{~N}$ layer of sample $\mathrm{A}$ indicates that the crystal is partially relaxed. The result for sample $B$ indicates that $\mathrm{Ga}_{x} \operatorname{In}_{1-x} \mathrm{~N}$ is subject to pseudomorphic growth. No geometrical surface structure was found in the optical microscope image or scanning electron microscope image for these samples. An infrared (IR) reflectance analysis for the LO phonon - plasmon coupling mode

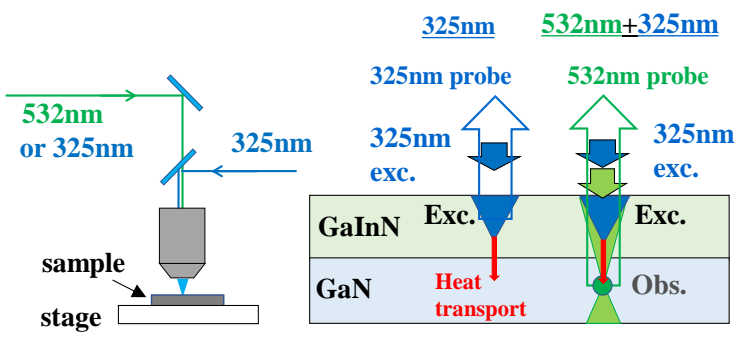

FIGURE 2: SCHEMATIC OF LASER IRRADIATION ON A SAMPLE AND CROSS-SECTIONAL DIAGRAM OF HETAT GENERATION (Exc.) AND RAMAN OBSEVATION (Obs.) IN THE MEASUREMENT SYSYTEM USING TWO LASERS.
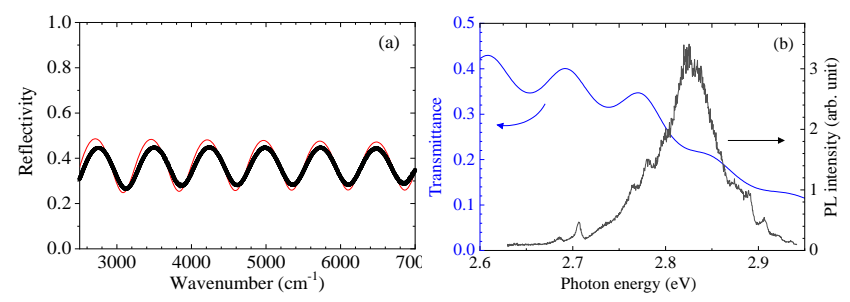

FIGURE 3: INFRARED REFLECTANCE SPECTRA IN IR REGION (a), AND EXAMPLE OF EXPERIMENTAL PL SPECTRA WITH CALCULATED TRANSMISSION SPECTRUM (b). THE THICK BALCK AND RED CURVES IN (a) SHOW THE EXPERIMENTAL SPECTRUM AND THE BEST-FIT THEORETICAL CURVE USING TRASFER MATRIX METHOD.

revealed that the residual electron density of this film of sample A was approximately $6 \times 10^{17} \mathrm{~cm}^{-3}$.

These samples were characterized by micro-Raman spectroscopy at $295 \mathrm{~K}$ with controlling spot positions of two lasers: $325 \mathrm{~nm}$ and $532 \mathrm{~nm}$. An objective lens with NA $=0.47$ and $\times 40$ was utilized. When beams of two different wavelengths were simultaneously incident on the same point on a sample surface, the 532-nm light was focused with a diameter of approximately $0.65 \mu \mathrm{m}$, while the $325-\mathrm{nm}$ light was diffused at an approximate diameter of $7 \mu \mathrm{m}$. The fluctuation of circumstance temperature was kept less than 1 degree. The Raman shift was calibrated using the $5460.7 \AA$ line of a Hg lamp. Using this system, we have observed anisotropic heat transport in the $\mathrm{GaInN} / \mathrm{GaN}$ heterostructures by analyzing images of Raman signals for the $\mathrm{E}_{2}{ }^{\mathrm{H}}$ and $\mathrm{A}_{1}{ }^{\mathrm{L}}$ in $8-15 \mu \mathrm{m}$ square regions. FIGURE 2 shows the geometric condition of the laser irradiation on a sample and the cross-sectional schematic of heating and Raman probing. The 325-nm excitation laser is used for heat generation in the GaInN layers by the energy relaxation of photogenerated carriers to the band edges. When the same laser beam is utilized to probe the Raman signal, the energy shift of a Raman peak reveals an increase in temperature in a GaInN layer. When the Raman signal is probed by the 532-nm laser, which penetrates to the $\mathrm{GaN}$ underlayer, the increase in the temperature of the GaN layer is probed. The relaxation energy of excited carriers to the band bottoms is expected to be $27 \%$ of the excitation energy for sample A. For sample B, generated energy is estimated to be $30 \%$ of that of sample A. Further energy transfer to the lattice vibration system is possible through nonradiative carrier recombination. The density of free carriers generated by a $1 \mathrm{~mW}$ excitation of the $325-\mathrm{nm}$ beam was estimated to be approximately $5.55 \times 10^{13} \mathrm{~cm}^{-2}\left(5 \times 10^{18} \mathrm{~cm}^{-3}\right.$ for sample A) or less by considering the lifetime of shorter than 500 ps. Carrier diffusion in the $\mathrm{Ga}_{x} \mathrm{In}_{1-x} \mathrm{~N}$ layers further decreases the carrier density to approximately one quarter. In simultaneous excitation, the carrier density is estimated to be less than $10^{17} \mathrm{~cm}^{-}$ ${ }^{3}$ for the excitation laser power of $10 \mathrm{~mW}$ for sample A. In these cases, the thermal energy conduction by free carriers can be neglected [9]. In sample B, the generated carriers are estimated to be confined in the vicinity of the surface. 


\section{RESULTS AND DISCUSSION}

\subsection{Photoluminescence properties}

FIGURE 3(a) shows an infrared reflectance spectrum of sample A, where the incidence angle is $60^{\circ}$ from the surface normal. In the observed energy region, the electric permittivity is nearly constant. The theoretical spectrum fitted using the relative dielectric constant at the infinite frequency of 5.35 is plotted by the red line, which satisfactorily agrees with the experimental result. The film thickness values of the GaInN and $\mathrm{GaN}$ were obtained to be $110 \mathrm{~nm}$ and $3060 \mathrm{~nm}$. The transmission spectrum was calculated using these parameters. FIGURE 3(b) shows an example of the photoluminescence (PL) spectra observed using an excitation laser of $325 \mathrm{~nm}$ and the calculated transmission spectrum for sample A. The amplitude of the spectrum oscillation by the optical interference in the transmission spectrum is decreasing with the increase in the photon energy. The PL spectrum is found to be scarcely affected by optical interference. FIGURE 4 shows PL intensity mappings. For sample A, dark lines parallel to $\langle 1 \overline{1} 00\rangle$ intersect mutually at an angle of $60^{\circ}$. This contrast in PL intensity is attributed to nonradiative carrier recombination (NR) in the vicinity of MDs on the $\mathrm{Ga}_{0.84} \mathrm{In}_{0.16} \mathrm{~N} / \mathrm{GaN}$ interface. For sample $\mathrm{B}$, the PL was found to be peaked at $2.88 \mathrm{eV}$ with a width of approximately 80 $\mathrm{meV}$. The mapping image shows no dark line, which indicates MDs are not observed in this region.

\subsection{Mode dependent energy transport properties in GalnN layers}

FIGURE 5 shows examples of Raman spectra. In FIGURE 5(b), the Raman spectrum obtained by the 532-nm laser is also exhibited by the blue curve, which is dominated by the signal from the n-GaN layer. In FIGURE 5(a), the obtained spectrum peak energies are shifted from those of the n-GaN substrate. Further, as the 325-nm laser light is absorbed within the depth of approximately $100 \mathrm{~nm}$ from the surface, the observed Raman peaks by using this laser for sample $A$ are attributed to the $\mathrm{E}_{2}{ }^{\mathrm{H}}$ and $\mathrm{A}_{1}{ }^{\mathrm{L}}$ modes of the GaInN layer. In FIGURE 5 (b), the $\mathrm{E}_{2}{ }^{\mathrm{H}}$ signal obtained by the $325-\mathrm{nm}$ laser is overlapped with the signal by the $532-\mathrm{nm}$ laser, whereas the $\mathrm{A}_{1}{ }^{\mathrm{L}}$ signal by the $325-\mathrm{nm}$ laser is shifted from the broad LO phonon - plasmon coupled (LOPC) mode peak of the $\mathrm{n}-\mathrm{GaN}$ layer. Using the concerned deformation potentials of $\mathrm{Ga}_{x} \mathrm{In}_{1-x} \mathrm{~N}$ obtained by the linear interpolation between the values of GaN and $\mathrm{InN}$ listed in Table I [33-39], and the mode energies of relaxed materials $[40,41]$, the mode
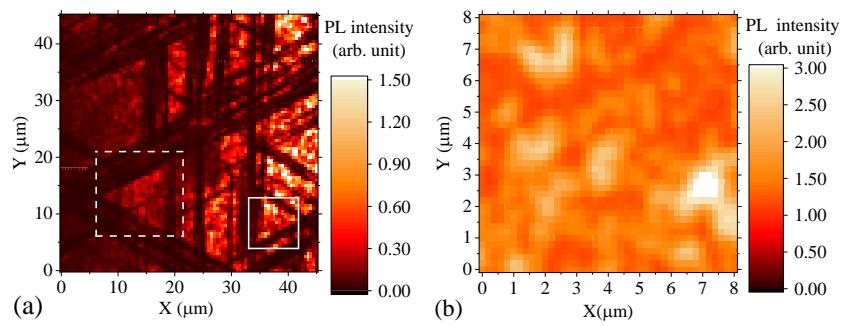

FIGURE 4: MAPPING IMAGES OF PL SPECTRUM INTENSITY FOR SAMPLE A (a) ${ }^{30)}$ AND SAMPLE B (b).
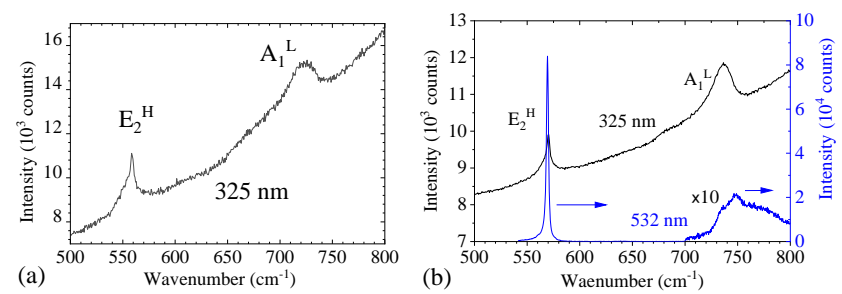

FIGURE 5: RAMAN SPECTRUM EXAMPLES USING THE 325-NM EXCITATION FOR SAMPLE A (a) ${ }^{30)}$ AND SAMPLE B (b).

energies of strained materials were calculated. As a result, pseudomorphic $\mathrm{Ga}_{x} \mathrm{In}_{1-x} \mathrm{~N}$ alloys in the alloy composition range of $0.83 \leq \mathrm{x} \leq 1.0$ have $\mathrm{E}_{2}{ }^{\mathrm{H}}$ energy in the range of $567-576\left(\mathrm{~cm}^{-}\right.$ $\left.{ }^{1}\right)$, and $\mathrm{A}_{1}^{\mathrm{L}}$ energy in the range of $736-728\left(\mathrm{~cm}^{-1}\right)$. Thus, the observed $\mathrm{A}_{1}{ }^{\mathrm{L}}$ peak by the $325-\mathrm{nm}$ laser for sample $\mathrm{B}$ is attributed to the superposition of the signals from various $\mathrm{Ga}_{x} \mathrm{In}_{1-x} \mathrm{~N}$ crystals in the range of $0.83 \leq \mathrm{x} \leq 1.0$. For the $\mathrm{E}_{2}{ }^{\mathrm{H}}$ peak, although the $\mathrm{E}_{2}{ }^{\mathrm{H}}$ phonon energies of pseudomorphic $\mathrm{Ga}_{x} \mathrm{In}_{1-x} \mathrm{~N}$ in $0.83 \leq \mathrm{x}$ $\leq 1.0$ are included in a small range of $9 \mathrm{~cm}^{-1}$, we can not exclude the possibility that the spectrum peak includes the signal generated by the small fraction of the laser light penetrated to the $\mathrm{n}-\mathrm{GaN}$. In this case, the signal probes the phonon modes in the region of less than $100 \mathrm{~nm}$ from the interface with the GaInN layer, which indicates that the temperature increase in a small region of $\mathrm{GaN}$ facing the $\mathrm{GaInN}$ possibly affects the signal.

The mapping images of these peak energies in the dashed square region of sample A in FIGURE 4 are shown in FIGURE 6 . The images of the $\mathrm{E}_{2}{ }^{\mathrm{H}}$ mode show the same triangular shape as observed in the PL intensity mapping, which indicates that the InN mole fraction or the magnitude of the strain depends on the density of MD. By increasing the intensity of the $325-\mathrm{nm}$ excitation laser from 1.1 to $11(\mathrm{~mW})$, the mode energy is found to be decreased, and the contrast of the triangular structure
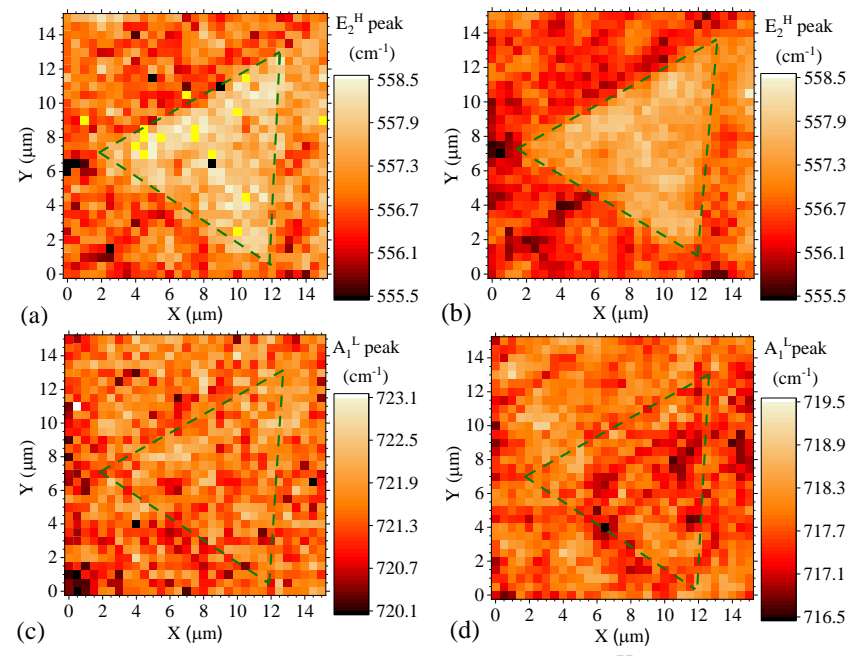

FIGURE 6: MAPPING IMAGES OF THE $\left.\mathrm{E}_{2}{ }^{\mathrm{H}}(\mathrm{a})^{30}\right) \mathrm{AND}(\mathrm{b})^{30)}$, AND $A_{1}{ }^{\mathrm{L}}$ (c) AND (d) OF THE GaInN LAYER. (a) AND (c) ARE FOR THE EXCITATION POWER OF $1.1 \mathrm{~mW}$, AND (b) AND (d) ARE FOR $11 \mathrm{~mW}$. 
TABLE 1: PARAMETERS FOR ANISOTROPIC STRAIN AND LATTICE VIBRATION OF GaN AND InN.

\begin{tabular}{cccccccc}
\hline & & $a\left(\mathrm{~cm}^{-1}\right)$ & $b\left(\mathrm{~cm}^{-1}\right)$ & $v$ & $\begin{array}{c}\alpha_{\mathrm{th} / /} \\
\left(10^{-6} \mathrm{~K}^{-1}\right)\end{array}$ & $\begin{array}{c}\mathrm{d} \omega / \mathrm{d} T \\
\left(10^{-2} \mathrm{~cm}^{-1} \mathrm{~K}^{-1}\right)\end{array}$ & $\omega_{0}\left(\mathrm{~cm}^{-1}\right)$ \\
\hline $\mathrm{GaN}$ & $\mathrm{E}_{2}{ }^{\mathrm{H}}$ & $-742[33]$ & $-715[33]$ & $0.183[34]$ & $4.2[37]$ & $-0.87[34]$ & $568.5[33], 567.6[39]$ \\
& $\mathrm{A}_{1}{ }^{\mathrm{L}}$ & $-664[33]$ & $-882[33]$ & $0.25-0.33[33]$ & & $-2.4[33]$ & $736.4[33]$ \\
$\mathrm{InN}$ & $\mathrm{E}_{2}{ }^{\mathrm{H}}$ & $-938[35]$ & $-407[35]$ & $0.21[35]$ & $3.83[36]$ & $-13[38]$ & $494.6[35]$ \\
& $\mathrm{A}_{1}{ }^{\mathrm{L}}$ & $-901[35]$ & $-587[35]$ & $0.27[34]$ & & $-6.0[38]$ & $582.3[35]$ \\
\hline
\end{tabular}

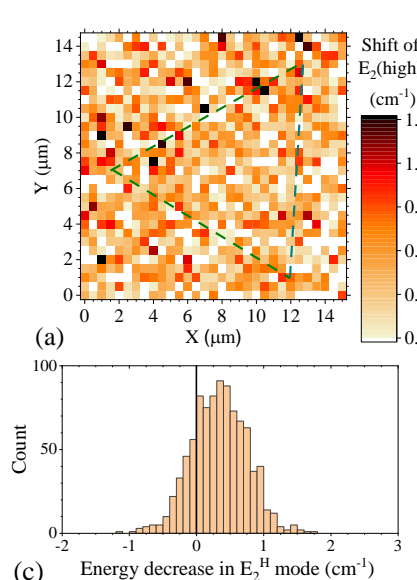

(c) Energy decrease in $\mathrm{E}_{2}{ }^{\mathrm{H}}$ mode $\left(\mathrm{cm}^{-1}\right)$
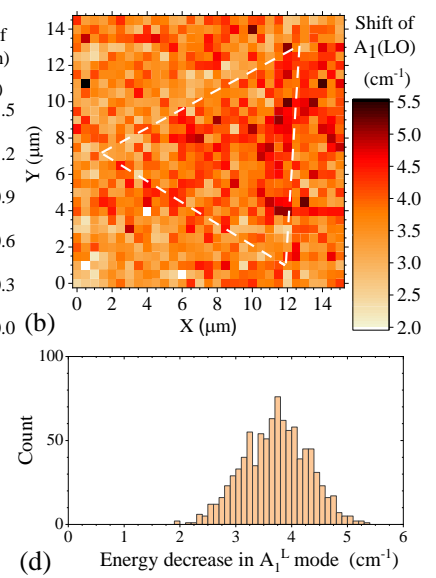

FIGURE 7: MAPPING IMAGES OF THE DECREMENTS OF THE MODE ENERGIES BY INCREASING THE 325-nm LAER POWER FOR THE $E_{2}{ }^{\mathrm{H}}\left(\mathrm{a}^{30}\right)$ AND $\mathrm{A}_{1}^{\mathrm{L}}$ (b), AND HISTOGRAMS OF THE DECREMENTS IN THE OBSERVED AREA FOR THE $\mathrm{E}_{2}{ }^{\mathrm{H}}$ (c) ${ }^{30)} \mathrm{AND} \mathrm{A}_{1}^{\mathrm{L}}(\mathrm{d})$.

becomes clear as shown in FIGURE 6(b). This result indicates the crystal temperature increases by increasing the laser intensity. In contrast to this result, the images of the $\mathrm{A}_{1}{ }^{\mathrm{L}}$ in FIGURE 6(c) and (d) show no clear triangular structure even by increasing the excitation power to $11 \mathrm{~mW}$. At a further lower excitation power of $0.1 \mathrm{~mW}$, the $\mathrm{A}_{1}{ }^{\mathrm{L}}$ peak energies inside and outside the triangular structure were measured, because imaging measurement requires too much time when using such a low excitation laser intensity. As a result, it was found that the energy of this mode inside the triangle is greater than that outside the triangle. Thus, the $\mathrm{A}_{1}{ }^{\mathrm{L}}$ energies at the low excitation power limit show a property consistent with the mapping image for the $\mathrm{E}_{2}{ }_{2}^{\mathrm{H}}$. FIGURES 7 (a) and (b) show the decrements in the respective mode energies by increasing the laser power. The decrement in the $\mathrm{A}_{1}{ }^{\mathrm{L}}$ energy is greater than that in the $\mathrm{E}_{2}{ }^{\mathrm{H}}$ mode energy. This phenomenon can not be attributed to LOPC. This is because both of the energies of the higher and lower energy branches of the LOPC modes increase with the increase in the electron density. FIGURES 7 (c) and (d) show histograms of the variations of the mode energies, which indicate the shift of the mean mode energy of the $\mathrm{A}_{1}{ }^{\mathrm{L}}$ is seven times greater than that of the $\mathrm{E}_{2}{ }^{\mathrm{H}}$. This result indicates that a phenomenon peculiar to the $\mathrm{A}_{1}{ }^{\mathrm{L}}$ is observed.
Candidate factors affecting this phenomenon are an extraordinal increase in the occupation factor of the $\mathrm{A}_{1}{ }^{\mathrm{L}}$ by heating and the greater shift of the Raman peak energy of the $\mathrm{A}_{1}{ }^{\mathrm{L}}$. The parameters to analyze the mode energies are listed in Table I. We assume that the shift of mode energy $\Delta \omega$ by strain is expressed as $2 a \varepsilon_{\mathrm{xx}}+b \varepsilon_{\mathrm{zz}}$, which is transformed to

$$
\Delta \omega=[2 a-2 b v /(1-v)] \varepsilon_{\mathrm{xx}}
$$

Here, $\varepsilon_{\mathrm{xx}}, \varepsilon_{\mathrm{zz}}$, and $v$ are strains in $\mathrm{x}$ and $\mathrm{z}$ directions, and Poisson ratio, respectively. The notations of $a$ and $b$ are the deformation potentials. When we adopt the potential values of $a=742 \mathrm{~cm}^{-1}$ and $b=715 \mathrm{~cm}^{-1}$ for the $\mathrm{E}_{2}{ }^{\mathrm{H}}, v=0.25$ for GaN, and the mode energies for $\mathrm{Ga}_{x} \mathrm{In}_{1-x} \mathrm{~N}$ alloys in references 40 and 41 , the observed mode energy for the $\mathrm{E}_{2}{ }^{\mathrm{H}}$ is lower than the calculated pseudomorphic $\mathrm{Ga}_{0.84} \mathrm{In}_{0.16} \mathrm{~N}$ layer, although the computed value of the $\mathrm{A}_{1}{ }^{\mathrm{L}}$ is consistent to the experimentally observed mode energy. This result indicates that the crystal is relaxed to some extent even inside the triangular shape region, and that the $\mathrm{A}_{1}^{\mathrm{L}}$ energy is affected by LOPC originating from the photoexcited electrons, while the temperature increase affects the peak energy shift of the $\mathrm{A}_{1}{ }^{\mathrm{L}}$ dominantly. Here, the parameters of $\mathrm{Ga}_{x} \mathrm{In}_{1-x} \mathrm{~N}$ excluding mode energies were obtained by the linear interpolation of the values of $\mathrm{GaN}$ and $\mathrm{InN}$.

When we assume that the temperature increase of the sapphire substrate excluding the vicinity of the interface is negligible, and the Poisson ratio is constant, the energy shift of the $\mathrm{E}_{2}{ }^{\mathrm{H}}$ peak by increasing the laser power of $325 \mathrm{~nm}, \Delta E\left(\mathrm{E}_{2}{ }^{\mathrm{H}}\right)$, is expressed in the following equation by considering the thermal strain.

$$
\Delta E\left(\mathrm{E}_{2}{ }^{\mathrm{H}}\right) \approx \Delta E\left(\mathrm{E}_{2}^{\mathrm{H}}: T-T_{0}, 0\right)-C_{\mathrm{E}} \cdot \alpha_{\mathrm{th} / /} \cdot\left(T-T_{0}\right)
$$

Here, $C_{\mathrm{E}}$ is the coefficient presenting the dependence of mode energy on in-plane strain $\varepsilon_{\mathrm{xx}}$ shown in Eq. (1). The linear thermal expansion coefficient is denoted as $\alpha_{\mathrm{th}} / / . \Delta E\left(\mathrm{E}_{2}{ }^{\mathrm{H}}: T-T_{0}, 0\right)$ is the decrease in the mode energy by increasing temperature from $T_{0}$ to $T$ for bulk crystal without thermal stain. $\Delta E\left(\mathrm{E}_{2}{ }^{\mathrm{H}}\right)$ is found to be $2.4 \times 10^{-3} \cdot \Delta T\left(\mathrm{~cm}^{-1}\right)$ using the parameters in Table I. The energy shift of $0.5 \mathrm{~cm}^{-1}$ for the $\mathrm{E}_{2}^{\mathrm{H}}$ of sample A corresponds to a temperature increase of $21 \mathrm{~K}$ with an increase in the excitation power of the 325-nm light, whereas the increase for the $\mathrm{A}_{1}{ }^{\mathrm{L}}$ mode is calculated to be $130 \mathrm{~K}$ at least. As no notch filter for the 325- 

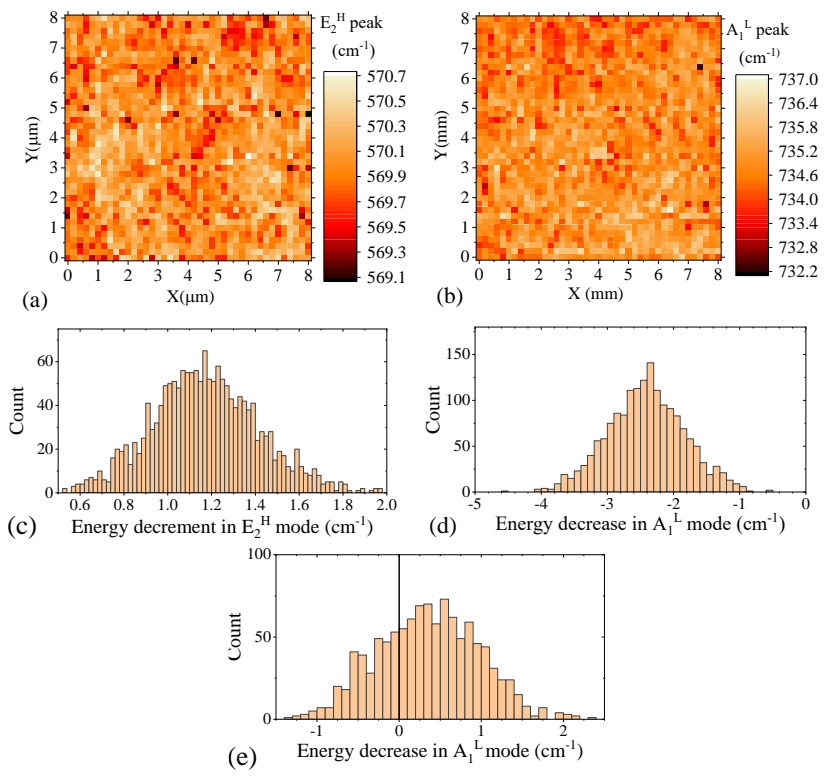

FIGURE 8: MAPPING IMAGES OF RAMAN PEAK ENERGIES FOR THE $\mathrm{E}_{2}{ }^{\mathrm{H}}$ (a) AND $\mathrm{A}_{1}^{\mathrm{L}}$ (b) BY THE 325-nm EXCITATION $(10 \mathrm{~mW})$ FOR SAMPLE B, AND THE DECREMENTS IN THE MODE ENERGIES BY INCREASING THE EXCIATATION POWER FROM $1 \mathrm{~mW}$ TO $10 \mathrm{~mW} \mathrm{FOR} \mathrm{E}_{2} \mathrm{H}$ (c) AND $\mathrm{A}_{1}^{\mathrm{L}}$ (d), AND FROM $2 \mathrm{~mW}$ TO $5 \mathrm{~mW}$ FOR $\mathrm{A}_{1}^{\mathrm{L}}$ (e).

nm excitation was available in the present experiment, the ratio of Anti-Stokes and Stokes signal intensities was not investigated. Instead, this intensity ratio is discussed using an $\mathrm{InN}$ film (4.5$\mu \mathrm{m}$ thickness) on a GaN layer and the 532-nm laser, where the intensity ratio of anti-Stokes $\left(I_{\mathrm{AS}}\right)$ and Stokes $\left(I_{\mathrm{S}}\right)$ signals were investigated using the following equation.

$$
\frac{I_{A S}}{I_{S}}=\left(\frac{\omega_{0}+\omega_{p h}}{\omega_{0}-\omega_{p h}}\right) \exp \left(-\frac{\hbar \omega_{p h}}{k_{b} T}\right)
$$

Here, $\omega_{0}, \omega_{\mathrm{ph}}, k_{\mathrm{b}}$, and $T$ are the frequency of the incident laser, phonon frequency, Boltzmann factor, and temperature, respectively. Since the energy gap of the InN layer is $0.63 \mathrm{eV}$ at room temperature [42], the excitation using the 532-nm laser provides enough carrier relaxation energy. When the excitation energy was increased from 14 to $20(\mathrm{~mW})$, we have found a temperature increase from 311 to $316(\mathrm{~K})$ for the $\mathrm{A}_{1}{ }^{\mathrm{L}}$, while no temperature increase for the $E_{2}{ }^{H}$. Thus, the occupation of the $A_{1}{ }^{L}$

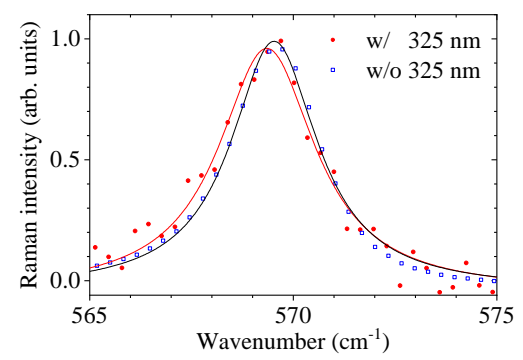

FIGURE 9: SPECTRA OF THE $\mathrm{E}_{2}{ }^{\mathrm{H}}$ WITH AND WITHOUT THE 325-nm EXCITATION ${ }^{30)}$.
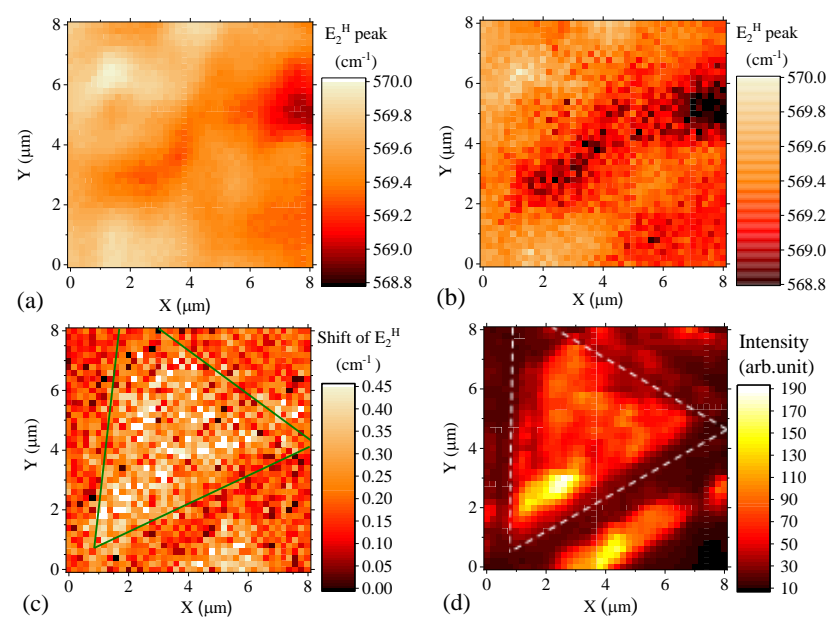

FIGURE10: RAMAN IMAGES BY THE 532-nm LASER WIHTOUT (a) ${ }^{30)}$ AND WITH (b) THE 325-nm LAER IRRADIATION, AND DECREMENT OF THE PEAK ENERGY BY IRRADIATING THE 325-nm LAESR (c) ${ }^{30)}$. MAPPING OF THE PL INTENSITY FROM THE GaInN LAYER IS PLOTTED IN (d) ${ }^{30)}$.

is thought to be increased by the electronic band to band transition and the subsequent carrier energy relaxation. It is thought that this phenomenon can not be attributed to a mechanism based on any temperature increase originating from the increase in the occupation factor of acoustic phonon modes, which induces the lattice dilatation and the resultant decrease in energy of every phonon mode.

The featureless images of the decrement of the Raman peak energies shown in FIGURE 7 indicate that thermal energy transport is independent of the defects on the $\mathrm{Ga}_{x} \mathrm{In}_{1-x} \mathrm{~N} / \mathrm{GaN}$ interface. Two mechanisms are considered: (1) long diffusion length of thermal energy with respect to the size of the triangle and (2) dominant thermal conduction on the surface side $\mathrm{Ga}_{x} \mathrm{In}_{1-}$ ${ }_{x} \mathrm{~N}$ layer with higher crystal quality than that of the crystal in the vicinity of MDs located on the heterointerface. In PL analysis, it was found that the PL spectra in the dark PL region in FIGURE 4 have another peak at $2.75 \mathrm{eV}$, which indicates that the PL peak at $2.82 \mathrm{eV}$ originates from the crystals with improved quality. In the dark region, this $\mathrm{PL}$ component originating from the improved crystal quality is included, which suggests that the quality of crystal in the vicinity of the surface is improved even in the dark PL region. The energy transport along this improved crystal regions possibly induces long heat energy diffusion over the size of the triangle.

FIGURE 8 shows the Raman mapping images for sample $\mathrm{B}$, where the triangle shape is not observed, which is consistent with the result of the PL mapping image shown in FIGURE 4 (b). The histograms of the decrements of the two mode energies are shown in FIGURES 8 (c), (d), and (e). As the observed Raman peak in the vicinity of $570 \mathrm{~cm}^{-1}$ is possibly the overlap of the peaks for the GaInN and GaN layers, the temperature of the GaInN layer or the GaN in the vicinity of the GaInN layer is increased by $170 \mathrm{~K}$ at least. At present, the reason for this high 


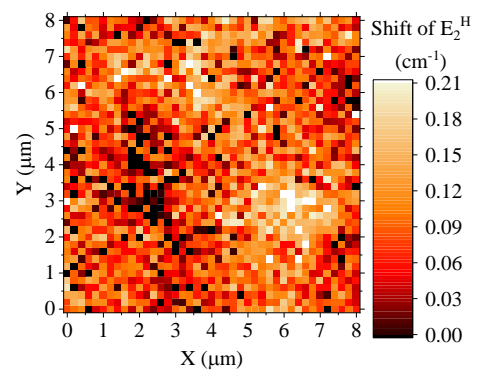

FIGURE 11: MAPPING IMAGE OF THE DECREMENT OF THE $\mathrm{E}_{2}{ }^{\mathrm{H}}$ PEAK ENERGY OF SAMPLE B BY IRRADIATING THE 325-nm LAESR.

temperature increase is not solved. However, phonon confinement in the region with lower $x$ (lower phonon mode energy) in the $\mathrm{Ga}_{x} \mathrm{In}_{1-x} \mathrm{~N}$ layer with graded alloy composition may be a candidate reason. On the other hand, the $\mathrm{A}_{1}{ }^{\mathrm{L}}$ energy increases by increasing the power from 1 to $10(\mathrm{~mW})$, while the decrease in the mode energy is observed for a small increase in the excitation power from 2 to $5(\mathrm{~mW})$ as shown in FIGURE 8(e). These results indicate that the temperature increase takes place also for the $A_{1}{ }^{\mathrm{L}}$. As carrier confinement in the vicinity of the surface in this sample takes place, the increase in the LOPC mode energy is dominant when the excitation power is high. Thus, the analysis for the $\mathrm{A}_{1}{ }^{\mathrm{L}}$ is complicated because of the two effects of an increase in temperature and an increase in electron density.

\subsection{Energy transport from the GalnN layer to the underlying GaN}

FIGURE 9 shows an example of Raman spectra obtained by the 532-nm line with and without the simultaneous irradiation of the 325-nm laser for sample A. The spectrum peak at approximately $569 \mathrm{~cm}^{-1}$ is attributed to the $\mathrm{E}_{2}{ }^{\mathrm{H}}$ mode of the GaN film. FIGURES 10 (a) and (b) show the mapping images of the peak energy obtained by Lorentzian fitting for the region indicated by the white solid square line in FIGURE 2. The variation in the mode energy in this area is within $1.1 \mathrm{~cm}^{-1}$, which corresponds to the strain variation of approximately $0.12 \%$. When the $325-\mathrm{nm}$ light with a power of $20 \mathrm{~mW}$ is incident on the sample, the mode energy is found to shift to the lower energy side, which indicates an increase in temperature. The obtained mapping of the decrement in the mode energy is plotted in FIGURE 10(c). The observed image exhibits the same triangular structure as observed in the PL intensity image shown in FIGURE 10(d) and the image of the $\mathrm{E}_{2}{ }^{\mathrm{H}}$ energy of the GaInN layer. The decrease in the $\mathrm{E}_{2}{ }^{\mathrm{H}}$ energy of the $\mathrm{GaN}$ film in the bright PL region is more significant than that in the area including MDs and exhibiting low PL intensity. This result indicates that the temperature increase in the $\mathrm{GaN}$ region under the GaInN layer with lower MD density is higher than that in the area outside the triangle rim with a higher density of MDs. The increase in temperature within the triangle is estimated to be approximately $56 \mathrm{~K}$, which is an average value in the region probed by the 532-nm light. Detail investigation on thermal

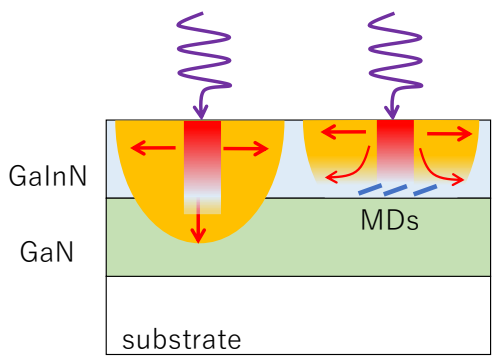

FIGURE 12: SCHEMATIC OF THE BLOCKING OF HEAT ENERGY TRANSPORT IN THE EXTENT OF MDS ON THE HETEROINTERFACE.

strain and the physical parameters are required for further analysis.

FIGURE 11 shows the mapping image of the decrement of the $\mathrm{E}_{2}{ }^{\mathrm{H}}$ energy by irradiating the $325-\mathrm{nm}$ light on sample $\mathrm{B}$. The measurement area is not the same as the area in FIGURE 4(b) or FIGURE 8. No MD structure is observed for this sample. The magnitude of the decrease in the $\mathrm{E}_{2}{ }^{\mathrm{H}}$ energy is approximately a half of that for sample A. It is estimated that the smaller decrement in the mode energy for sample B originates from the lower relaxation energy of carriers in the GaInN layer of sample $\mathrm{B}$, while for the further quantitative discussion, it is required to investigate the phonon transport in the GaInN layer with graded alloy composition and phonon generation by nonradiative carrier recombination.

The schematic of the heat transport in the present samples is depicted in FIGURE 11. It is believed that the extent of MDs blocks the heat transport from the GaInN layer to the underlying $\mathrm{GaN}$, while lateral heat transport in the $\mathrm{Ga}_{x} \mathrm{In}_{1-x} \mathrm{~N}$ layer of sample A takes place primarily via the crystal in the surface side region with improved crystal quality.

\section{CONCLUSION}

The Raman imaging using two lasers with different wavelengths is practical to analyze the heat energy transport at heterointerfaces. We have found the heat energy transport through the GaInN/GaN interface is blocked at MDs. Further, LO phonon can be separately analyzed from the energy transport observed for the $\mathrm{E}_{2}{ }^{\mathrm{H}}$ mode, where it is required to discuss the two factors of the temperature increase and the increase in electron density. We have found that LO phonon transport property is quite different from that of the $\mathrm{E}_{2} \mathrm{H}$.

\section{ACKNOWLEDGEMENTS}

This study was partly supported by the Grant-in-Aid for Scientific Research of the Japan Society for the Promotion of Science (16H06425 and 17H02772) and King Abdullah University of Science and Technology (KAUST) (BAS/1/167601-01)

\section{REFERENCES}

[1] I. Jabbari, M. Baira, H. Maaref, and R. Mghaieth, Physica E 104, 216 (2018). 
[2] C. Gaquière, H. Maaref , J. Phys. Chem. Sol. 132, 157 (2019).

[3] M. S. Ferdous, X. Wang, M. N. Fairchild, and S. D. Hersee, Appl. Phys. Lett. 91, 231107 (2007).

[4] Y. Ishitani, K. Takeuchi, N. Oizumi, H. Sakamoto, B. Ma, and K. Morita, H. Miyake, and K. Hiramatsu, Journal of Physics D 49, 245102 (2016).

[5] K. Oki, B. Ma, and Y. Ishitani, Phys. Rev. B 96, 205204 (2017).

[6] Y. Ishitani, K. Oki, and H. Miyake, Jpn. J. Appl. Phys. 58, SCCB34 (2019).

[7] K. Oki and Y. Ishitani, Journal of Applied Physics 125, 205705 (2019).

[8] J. Ma, X. Wang, B. Huang, and X. Luo, J. Appl. Phys. 114, 074311 (2013).

[9] T. E. Beechem, A. E. McDonald, E. J. Fuller, A. A. Talin, C. M. Rost, J.-P. Maria, J. T. Gaskins, P. E. Hopkins, and A. A. Allerman, J. Appl. Phys. 120, 095104 (2016).

[10] R. Aghababaei, G. Anciaux, and J.-F. Molinari, , Appl. Phys. Lett. 105, 194102 (2014)

[11] G. Chen and M. Neagu, Appl. Phys. Lett. 71, 2761 (1997).

[12] R. Anufriev, A. Ramiere, J. Maire, and M. Nomura, Nat. Commun. 16, 15505 (2017).

[13] G. Zeng, P. Harrison, A. Kidman, A. Almebir, L. Feng, and J. Wu, Appl. Spectr. 70, 1555 (2016).

[14] X. Tang, S. Xu, and X. Wang, Plos one 8, e58030 (2013).

[15] M. Kuball, S. Rajasingam, A. Sarua, M. J. Uren, T. Martin, B. T. Hughes, K. P. Hilton, and R. S. Balmer, Appl. Phys. Lett. 82, 124 (2003).

[16] M. Kuball, G. J. Riedel, J. W. Pomeroy, A. Sarua, M. J. Uren, T. Martin, K. P. Hilton, J. O. Maclean, and D. J. Wallis, IEEE Elec. Devices Lett. 28, 86 (2007).

[17] R. J. Simms, J. W. Pomery, M. J. Uren, T. Martin, and M. Kuball, Appl. Phys. Lett. 93, 203510 (2008).

[18] C. Hodges, J. Pomeroy, and M. Kuball, J. Appl. Phys. 115, 064504 (2014).

[19] B. Saha, Y. R. Koh, J. Comparan, S. Sadasivam, J. L. Schroeder, M. Garbrecht, A. Mohammed, J. Birch, T. Fisher, A. Shakouri, and T. D. Sands, Phys. Rev. B 93, 045311 (2016).

[20] Z. Liang, K. Saikumar, and P. Keblinski, Phys. Rev. Lett. 113, 65901 (2014).

[21] G. Chen and M. Neagu, Appl. Phys. Lett. 71, 2761 (1997).

[22] S.-M. Lee, D. G. Cahill, and R. Venkatasubramanian, Appl. Phys. Lett. 70, 2957 (1997).

[23] K. Kazan, Appl. Phys. Lett. 95, 141904 (2009).

[24] Z. Su, L. Huang, F. Liu, J. P. Freedman, L. M. Porter, R. F. Davis, and J. A. Malen, Appl. Phys. Lett. 100, 201106 (2012).

[25] E. Ziade, J. Yang, G. Brummer, D. Nothern , T. Moustakas, and A. J. Schmidt, Appl. Phys. Lett. 107, 091605 (2015).

[26] A. Pansari, V. Gedam, and B. K. Sahoo, J. Phys. Chem. Sol. 87, 177 (2015).

[27] Th. Pavloudis, K. Termentzidis, Ph. Komninou, C. D. Latham, P. R. Briddon, and J. Kioseoglou, J. Appl. Phys. 119, 074304 (2016).
[28] M. Iwaya, T. Yamamoto, D. Iida, Y. Kondo, M. Sowa, H. Matsubara, K. Ishihara, T. Takeuchi, S. Kamiyama, and I. Akasaki, Jpn. J. Appl. Phys. 54, 115501 (2015).

[29] T. Sugiyama, Y. Kuwahara, Y. Isobe, T. Fujii, K. Nonaka, M. Iwaya, T. Takeuchi, S. Kamiyama, I, Akasaki, and H. Amano, Appl. Phys. Exp. 4, 015701 (2011).

[30] S. Okamoto, N. Saito, K. Ito, B. Ma, K. Morita, D. Iida, K. Ohkawa, Appl. Phys. Lett. 116, 142107 (2020).

[31] K. Ohkawa, F. Ichinohe, T. Watanabe, K. Nakamura, and D. Iida, J. Cryst. Growth 512, 69 (2019).

[32] K. Ohkawa, Y. Uetake, M. Velazquez-Rizo, and D. Iida, Nano Energy 59, 569 (2019).

[33] M. Kuball and J. W. Pomeroy, IEEE Trans. Dev. Mat. Reliability 16, 667 (2016).

[34] M. A. Moram, Z. H. Barber, and C. J. Humphreys, J. Appl. Phys. 102, 023505 (2007).

[35] X. Wang, S.-B. Che, Y. Ishitani, and A. Yoshikawa, Appl. Phys. Lett. 89, 171907 (2006).

[36] K. Wang and R. R. Reeber, Appl. Phys. Lett. 79, 1602 (2001).

[37] Y. Oshima, T. Suzuki, T. Eri, Y. Kawaguchi, K. Watanabe, M. Shibata, and T. Mishima, J. Appl. Phys. 98, 103509 (2005)

[38] X. D. Pu, J. Chen, W. Z. Shen, H. Ogawa, and Q. X. Guo, J. Appl. Phys. 98, 033527 (2005).

[39] V. Y. Davydov, Y. E. Kitaev, I. N. Goneharuk, A. N. Smirov, J. Graul, O. Semchinova, D. Uffmann, M. B. Smirov, A. P. Mirgorodsky, and R. A. Evarestov, Phys. Rev. 58, 12899 (1998).

[40] M. R. Correia, S. Pereira, E. Pereira, J. Frandon, and E. Alves, Appl. Phys. Lett. 83, 4761 (2003).

[41] R. Oliva, J. Ibáñez, R. Cuscó, R. Kudrawiec, J. Serafinczuk, O. Martínez, J. Jiménez, M. Henini, C. Boney, A. Bensaoula, and L. Artús, J. Appl. Phys. 111, 063502 (2012).

[42] Y. Ishitani, Jpn. J. Appl. Phys. 53, 100204 (2014). 